\title{
An outbreak of refrigerant-induced acute hepatitis in Hong Kong
}

\author{
YM Kan *, CF Lau, WC Chan, WS Chan, YM Tung, CK Loo
}

\begin{abstract}
A B S T R A C T
We report a cluster of acute hepatitis in five airconditioning maintenance workers following accidental exposure to 2,2-dichloro-1,1,1trifluoroethane (HCFC-123). They presented to us with complaints of feverishness, generalised malaise, and epigastric discomfort. Their blood biochemistry tests were compatible with acute hepatitis. Viral hepatitis serology, tests for autoimmune hepatitis, and analyses for drugs and alcohol consumption were all negative. No focal hepatic lesion was detected by ultrasound imaging. Percutaneous liver biopsy samples were taken from two of them. The patients were managed with supportive treatment. All had spontaneous, but slow, recovery. Their liver function tests returned to normal after 4 months and
\end{abstract}

their outcomes were favourable. Physicians should be aware of this occupational disease entity.

\section{Hong Kong Med J 2014;20:548-51}

DOI: 10.12809/hkmj134012

YM Kan *, MB, BS, FHKAM (Medicine)

CF Lau, MRCP, FHKAM (Medicine)

WC Chan, MRCP

WS Chan, MB, BS, FHKAM (Medicine)

YM Tung, MRCP, FHKAM (Medicine)

CK Loo, MRCP, FHKAM (Medicine)

Department of Medicine and Geriatrics, Kwong Wah Hospital, Yaumatei, Hong Kong

* Corresponding author: kanym@ha.org.hk

\section{Case report}

A 30-year-old air-conditioning maintenance worker presented to the Accident and Emergency Department in September 2010 with complaints of feverishness, dry cough, general malaise, poor appetite, and epigastric discomfort for 1 week. His initial symptoms 1 week before included feverishness and dry cough. He took paracetamol $(500 \mathrm{mg}, 4$ times a day for 2 days) after consulting a general practitioner and diagnosed as having acute upper respiratory tract infection. Two days after visiting the general practitioner, he developed general malaise, nausea, and epigastric bloating. He had good past health and his family history was unremarkable. $\mathrm{He}$ was a social drinker and his last drink was almost 3 months ago. On physical examination, he was febrile and showed a tinge of jaundice. He was conscious and well-oriented. His pulse rate was 140 beats/min, the blood pressure was $130 / 75 \mathrm{~mm} \mathrm{Hg}$, and his body temperature was $39.3^{\circ} \mathrm{C}$. Abdominal examination showed right upper quadrant tenderness but no other sign of acute abdomen; Murphy's sign was negative.

Initial investigation showed elevated blood leukocyte count and mild thrombocytopenia (Table). His liver function tests were deranged and clotting profile was impaired. Serology for hepatitis A, B, $\mathrm{C}$ and $\mathrm{E}$, Epstein-Barr virus, and cytomegalovirus was negative. Tests for antinuclear antibodies and anti-smooth muscle antibodies were also negative.
His toxicology screening was negative, except for a serum paracetamol level of $77 \mathrm{mmol} / \mathrm{L}$ (taken 6 hours after the last dose of paracetamol). Ultrasound of the abdomen was unremarkable. His liver function tests further deteriorated after admission (Table) and he remained febrile. Computed tomography of the abdomen was then performed, which revealed minimal amount of ascites and non-specific pericholecystic fluid collection.

He received intravenous hydration and vitamin $\mathrm{K}$ as supportive treatment for his acute hepatitis. $\mathrm{He}$ remained fully oriented, and his serum ammonia level was normal.

Upon further enquiry, the patient recalled that he experienced dizziness, drunk feeling, and unsteady gait after exposure to a refrigerant during maintenance of an air-conditioning system in a computer server room with an area of around $200 \mathrm{~m}^{2}$. His job was to flush the air-conditioning system and pipeline with a cleansing refrigerant. He said he was not provided with any protective gear. He was, therefore, asked to call his co-workers to see if they had developed similar symptoms.

Eight workers worked in rotation for 2 weeks. They were posted to clean and repair the airconditioning system in an enclosed area without any local exhaust ventilation system. In the first week, they were not provided with any effective protective gears. They worked for 6 hours a day in the first week. In the next week, they were provided with 
$3 \mathrm{M}$ face masks and their work duration shortened to 3 hours a day because they felt dizzy during work and needed to leave the room for a rest. Thus, exposure to leaked refrigerant was estimated to be high in such an enclosed workplace in the absence of effective protective gear. All workers experienced headache, dizziness, unsteady gait, and drunk feeling 15 minutes after exposure to the chemical released. They also had symptoms of dry cough, runny nose, fever, malaise, and loss of appetite a few days later. One of them also noticed passing tea-coloured urine and two had epigastric bloating.

Four among his seven co-workers agreed to undertake laboratory investigations. They were all found to have deranged liver function tests compatible with acute hepatitis. All investigations including viral hepatitis serology, tests for autoimmune hepatitis, and analyses for drugs and alcohol consumption were found to be negative. The circumstantial evidence, together with the clinical and laboratory findings, made refrigerant-induced acute hepatitis highly likely in this group of airconditioning maintenance workers.

Percutaneous liver biopsy in one of the affected

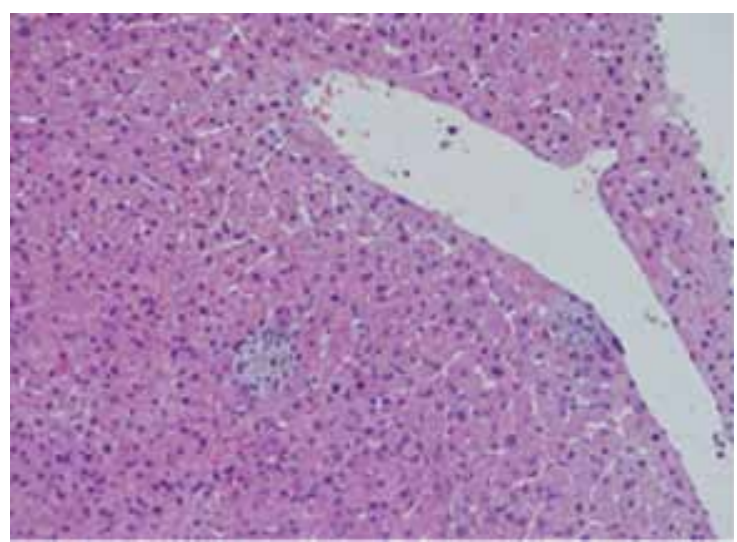

FIG. Liver biopsy: hepatocytic dropouts and mitotic figures in perivenular distribution (H\&E; original magnification, $x$ 40)

\section{因吸入雪種引致急性肝炎}

簡伊敏、劉植輝、陳偉聰、陳慧詩、董友民、陸正光

本文報告五宗因吸入 2,2-二氯-1,1,1-三氟乙烷（HCFC-123）而引致 集體急性肝炎的個案。病人病發時有發燒、疲倦及上腹不適。替病人 檢查發現血液肝酵素大幅上升。病毒性肝炎、自身免疫性肝炎測試以 及藥物和酒精分析均呈陰性。超聲顯像檢測並無發現任何肝臟結構性 病變。我們亦替其中兩名病人抽取活肝組織化驗。經過大概四個多月 的支緩性治療, 所有病人的肝酵素慢慢回復正常, 治療反應良好。醫 生應對這種職業病提高警覺。

patients revealed the presence of hepatocytic dropouts and mitotic figures in perivenular distribution. There was moderate lymphocytic infiltrate with scattered eosinophils in the portal areas with mild bile duct proliferation. Perivenular hepatocytic cholestasis was also evident (Fig). These features, coupled with the clinical history and laboratory findings, were in keeping with a diagnosis of hydrochlorofluorocarbons-related hepatitis.

However, urine analysis of volatile organic hydrocarbons, metabolites of 2,2-dichloro-1,1,1trifluoroethane (HCFC-123), on day 4 after admission of the index patient, turned out to be negative.

Over the following days, our index patient's symptoms improved progressively. His liver function tests, serum platelet count, and prothrombin time (given by the international normalised ratio) started to improve since day 5 of admission (Table). His coworkers' symptoms also improved gradually.

Four months later, the health conditions of all the workers were confirmed to be normal. Their liver function tests had normalised. All had favourable outcomes.

We reported the cases to the Labour Department and the Department of Health since

TABLE. Progression of the patient

\begin{tabular}{lccccc}
\hline & On admission & Day 4 & Day 10 & 4 Months later & Reference range \\
\hline Total white cell count $\left(\times 10^{9} / \mathrm{L}\right)$ & 12.9 & 15.2 & 12.7 & 9.9 & $4-10$ \\
Total platelet count $\left(\times 10^{9} / \mathrm{L}\right)$ & 122 & 92 & 340 & 350 & $150-500$ \\
INR & 1.36 & 1.49 & 1.19 & $<1.00$ & - \\
AST $(\mathrm{IU} / \mathrm{L})$ & 339 & 2173 & 251 & 18 & $<37$ \\
ALT (IU/L) & 210 & 1898 & 796 & 17 & $<45$ \\
ALP $(\mathrm{IU} / \mathrm{L})$ & 65 & 87 & 156 & 75 & $49-128$ \\
Serum bilirubin $(\mu \mathrm{mol} / \mathrm{L})$ & 31 & 62 & 49 & 14 & $<21$ \\
Serum albumin $(\mathrm{g} / \mathrm{L})$ & 34 & 27 & 31 & 44 & $35-50$ \\
\hline
\end{tabular}

Abbreviations: $\mathrm{ALP}=$ alkaline phosphatase; $\mathrm{ALT}$ = alanine aminotransferase; $\mathrm{AST}$ = aspartate aminotransferase; INR = international normalised ratio 
poisoning by halogen derivatives of hydrocarbon of the aliphatic series (ie HCFC-123) is a notifiable occupational disease in Hong Kong.

\section{Discussion}

HCFC-123 is a common refrigerant. It is one of the major substitutes for ozone-depleting chlorofluorocarbons used mainly as a refrigerant in chillers for industrial air-conditioning and in other applications such as foam blowing, cleansing agents, and industrial solvents. It is a colourless liquid with a light ether-odour and a boiling point of $27.6^{\circ} \mathrm{C} .{ }^{1}$

Acute exposure to HCFC-123 has been shown to produce severe hepatotoxicity in guinea pigs. ${ }^{2}$ A single acute exposure to $1000 \mathrm{ppm}$ of HCFC123 for 4 hours can cause increases in aspartate aminotransferase and alanine aminotransferase levels compatible with hepatocellular necrosis. Increased liver weight, focal liver necrosis, induction of peroxisomal activity and hepatocellular adenomas have been found in subchronic studies in rats and dogs. ${ }^{3}$

The mechanism of hepatotoxicity of HCFC123 was believed to be similar to that of 1-bromo-1chloro-2,2,2-trifluoroethane (halothane). Halothane is metabolised to form reactive trifluoroacetyl halide intermediates that can react with water to form trifluoroacetyl haptens which result in direct hepatotoxicity. Since HCFC-123 is metabolised in the same oxidative way as halothane, HCFC123 exposure might result in direct hepatotoxicity. In animal studies, the relative concentrations of trifluoroacetyl-protein adducts formed in the liver after administration of halothane and HCFC-123 were found to be similar. ${ }^{4}$ Alternatively, in-vitro metabolic studies of the human liver cytochrome P450 2E1 showed that exposure of human beings to HCFC-123 might result in higher concentrations of trifluoroacetyl-adducted liver proteins than those produced by halothane. The development of autoantibodies against P450 2E1 or P58 arising from immune reactions induced by trifluoroacetyladducted liver protein indicates that HCFC-related hepatotoxicity might also be immune-related. ${ }^{3}$

Takebayashi et $\mathrm{al}^{1}$ reported a cluster of acute liver dysfunction among workers exposed to HCFC123 for less than 5 hours. Nine out of 14 workers developed impairment of liver function tests and symptoms of poor appetite and abdominal pain. Alanine aminotransferase level went up to more than $1700 \mathrm{U} / \mathrm{L}$ in these patients, but all had a favourable outcome. By the end of 2 months after HCFC-123 exposure, their liver function tests had returned to normal. This revealed that the incidence of liver dysfunction after HCFC-123 exposure is high.

Hoet et $\mathrm{al}^{3}$ investigated an epidemic of liver disease in nine industrial workers who had repeated accidental exposure to a mixture of HCFC-123 and
HCFC-124. The results of this study also showed that repeated exposure of humans to HCFCs can result in serious liver injury in a high proportion of the exposed population. The liver biopsy showed hepatocellular necrosis which was prominent in perivenular zone 3 , and extended focally across portal tracts and to centrilobular areas. The hepatocyte dropout was well-developed. The leukocytic inflammatory infiltrates in the zones of necrosis were mononuclear. Trifluoroacetyl-adducted proteins were detected in surviving hepatocytes by immunohistochemical staining. Serum autoantibodies against P450 2E1 or P58, which are associated with halothane hepatitis, were also detected. In our index patient, the presence of hepatocytic dropouts, increased mitotic figures and eosinophils might suggest acute hepatitis and liver regeneration after a short period of refrigerant exposure.

At moderate levels of exposure to HCFC-123, such as in some occupational accidents or prolonged exposure in poorly ventilated areas, respiratory effects (cough, dyspnoea, and tachypnoea), central nervous system effects (dizziness, drowsiness, weakness, fatigue, numbness, and coma), and gastrointestinal upsets are characteristic. Hepatic injury (with elevated liver enzymes) and rhabdomyolysis might also rarely occur. ${ }^{5}$ A retrospective study showed that workers who had exposure to HCFC123 experienced symptoms related to the central nervous system, gastro-intestinal upset, and irritation of mucous membrane. ${ }^{6}$ These may include headache, dizziness, abdominal pain, nausea, vomiting, dyspepsia, irritating smell, and eye or throat irritation. ${ }^{6}$ The prevalence of these symptoms also increased in the high-exposure group. Moreover, the degree and prevalence of liver dysfunction were higher in the high-exposure group. ${ }^{7}$

Urinary concentration of trifluoroacetic acid (TFA), which is a major metabolite of HCFC-123, can be used to determine the degree of HCFC exposure in air. However, in our case, urinary concentration of HCFC metabolite was negative. A small-scale human study found that the concentration of TFA in the urine peaked at 20 to 30 hours, and returned to zero by 96 hours post-exposure. ${ }^{8}$ Since the urine sample of our index case was collected 4 days after exposure, a positive test would not be expected.

There is no specific antidotal treatment for liver injury related to HCFC exposure. Supportive treatment of liver dysfunction is recommended. Fortunately, the outcome of HCFC-related liver dysfunction is usually favourable. All our patients had spontaneous recovery after cessation of exposure. To our knowledge, there is no report of death or liver transplant due to HCFC-123-induced hepatitis.

Poisoning by HCFC exposure is a notifiable occupational disease in Hong Kong. We reported this outbreak to the Labour Department and the 
Department of Health so that the related parties could conduct investigations and recommend appropriate modifications in the relevant working environment. It is essential to implement strict measures to prevent HCFC exposure, and physicians should be aware of the potential toxicities following HCFC exposure.

\section{References}

1. Takebayashi T, Kabe I, Endo Y, et al. Acute liver dysfunction among workers exposed to 2,2-dichloro-1,1,1trifluoroethane (HCFC-123): a case report. J Occup Health 1998;40:169-70.

2. Marit GB, Dodd DE, George ME, Vinegar A. Hepatotoxicity in guinea pigs following acute inhalation exposure to 1,1-dichloro-2,2,2-trifluoroethane. Toxicol Pathol 1994;22:404-14.

3. Hoet P, Graf ML, Bourdi M, et al. Epidemic of liver disease caused by hydrochlorofluorocarbons used as ozone-sparing substitutes of chlorofluorocarbons. Lancet 1997;350:556-9.

4. Harris JW, Poul LR, Martin JL, Anders MW. Tissue acylation by the chlorofluorocarbon substitute 2,2-dichloro-1,1,1trifluoroethane. Proc Natl Acad Sci USA 1991;88:1407-10.

5. Concise International Chemical Assessment Document No. 23. Available from: http://www.inchem.org/ documents/cicads/cicads/cicad23.htm. Accessed Jun 2014.

6. Takebayashi T, Kabe I, Endo Y, et al. Exposure to 2,2-dichloro-1,1,1-trifluoroethane (HCFC-123) and acute liver dysfunction: a causal interference. J Occup Health 1998;40:334-8.

7. Boucher R, Hanna C, Rusch GM, Stidham D, Swan E, Vazquez M. Hepatotoxicity associated with overexposure to 1,1-dichloro-2,2,2-trifluoroethane (HCFC-123). AIHA J (Fairfax, Va) 2003;64:68-79.

8. Tanaka S, Kabe I, Takebayashi T, et al. Environmental and biological monitoring of 2,2-dichloro-1,1,1-trifluoroethane (HCFC-123). J Occup Health 1998;40:348-9. 